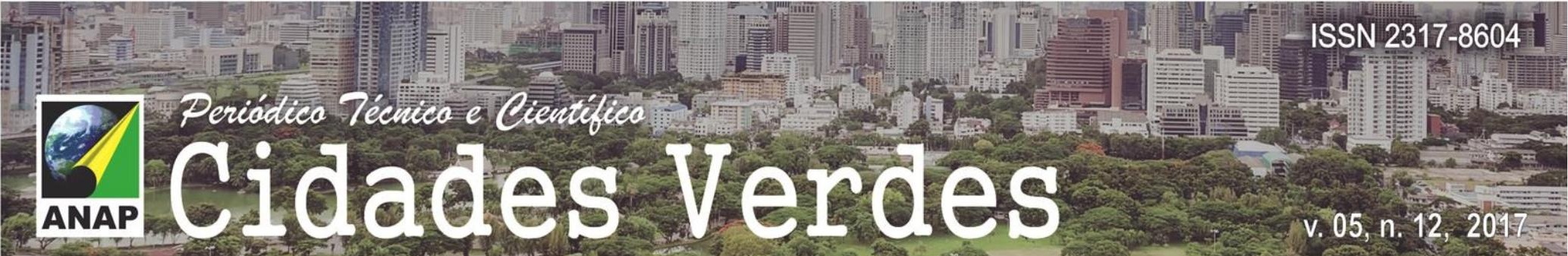

\title{
Estradas parque do ponto de vista da infraestrutura de transportes
}

Park roads (parkways) from the point of view of transport infrastructure

Parque carreteras desde el punto de vista de infraestructura de transporte

Daniela Rodrigues Ribeiro

Estudante de Engenharia Civil, UNESP, Brasil danielarribeiro.91@gmail.com

Jairo Salim Pinheiro de Lima

Professor Doutor, UNESP, Brasil jairo@dec.feis.unesp.br 


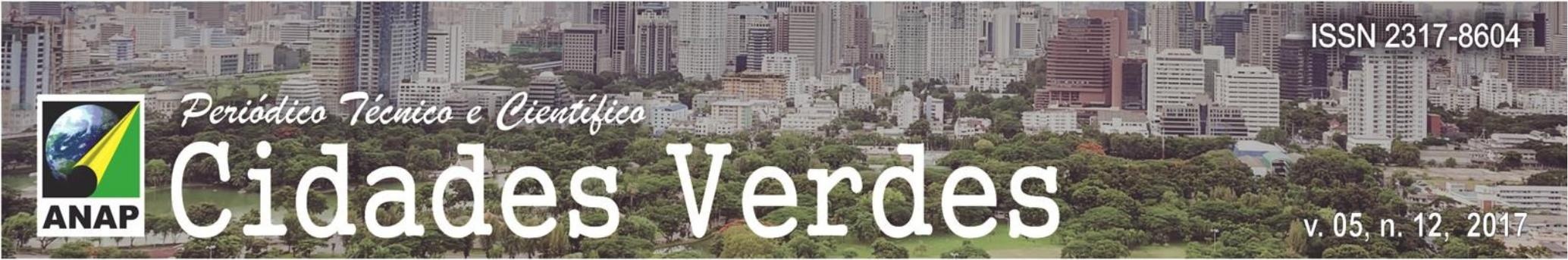

\section{RESUMO}

Estradas parque são estradas não convencionais do ponto de vista do projeto, construção, controle, operação e manutenção. Neste tipo de via, os parâmetros ambientais prevalecem. Mas as normas e as técnicas brasileiras disponíveis são ainda incipientes quando se tratam de estradas parque. O presente artigo visa definir o conceito para a estrada parque com base nas suas características típicas, relacionadas às técnicas e procedimentos tradicionalmente adotados em infraestrutura de transportes. As informações e os dados aqui apresentados estão substanciados na literatura específica da área de estradas e pavimentos, e em informes obtidos de folders, panfletos e divulgações de outros setores (da economia ao meio ambiente), dado que o funcionamento atual das estradas parques está intimamente vinculado ao turismo e ao lazer e menos à movimentação de cargas e pessoas.

PALAVRAS-CHAVE: Estradas parque. Rodovias especiais. Impactos ambientais em rodovias.

\section{ABSTRACT}

Park roads (parkways) are unconventional roads from the point of view of design, construction, control, operation and maintenance. In these roads, the environmental parameters take precedence. But the Brazilian standards and the techniques available are still incipient when dealing with park roads. This article aims to define the concept for the park road and its typical characteristics, related to techniques and procedures traditionally used in transport infrastructure. The information and data presented here are substantiated in the literature in the area of roads and pavements, and announcements obtained from brochures, flyers and announcements of other sectors (of the economy to the environment), given that the current functioning of the parks roads is closely linked to tourism and leisure and less moving products and people.

KEY WORDS: Park Roads. Parkways. Special roads. Environmental impacts on highways.

\section{RESUMEN}

Parque caminos son caminos no convencionales desde el punto de vista de diseño, construcción, control, operación y mantenimiento. En este tipo, los parámetros ambientales tienen prioridad. Pero las normas brasileñas y las técnicas disponibles son todavía incipientes cuando se trabaja con los caminos del parque. Este artículo pretende definir el concepto de la carretera del parque sobre la base de sus características típicas, relacionadas con técnicas y procedimientos utilizados tradicionalmente en infraestructura de transporte. La información y los datos presentados aquí están respaldados en la literatura en el área de carreteras y pavimentos y los anuncios obtenidos de folletos, volantes y anuncios de otros sectores (de la economía con el medio ambiente), dado que el funcionamiento actual de los caminos de parques está estrechamente vinculado al turismo y ocio y menos movimiento carga y personas.

PALABRAS CLAVE: Parque caminos. Carreteras especiales. Impactos ambientales en carreteras. 


\section{INTRODUÇÃO}

O conceito tradicional de estradas agrega fatores predominantemente econômicos e financeiros, relevando em plano secundário as variáveis vinculadas ao meio ambiente. Embora os mecanismos de controle ambiental sejam rigorosos, as estradas constituem ainda fortes agentes de impactos e de alterações ambientais. Por isso, compatibilizar desenvolvimento e manutenção das qualidades ambientais continua um desafio imperativo.

Estradas são obras lineares e atravessam diferentes ecossistemas e adotar os mesmos projeto e procedimentos construtivos em toda a sua extensão não parece oportuno. A diversidade impõe a necessidade de empregar técnicas especiais em meios especiais. Regiões com alta vulnerabilidade ambiental, por exemplo, requerem alternativas de projeto, de materiais, construtivas e operacionais específicas. É o caso das unidades de conservação.

É saliente observar que o elenco de impactos gerados na construção e operação de estradas abriga diferentes configurações como: impactos permanentes (fragmentação de cenários); impactos dinâmicos (pressão sobre áreas lindeiras); impactos cumulativos (acidentes). Bons projeto e planejamento (anteriores à construção e operação) tendem a reduzir tais dissonâncias. Buscando minimizar os efeitos dos impactos negativos das estradas, Lima (2010), com base em proposições da Funtac, sugere princípios para fortalecer as interações ambientais das estradas com o seu entorno.

a) Inevitabilidade. A construção de uma estrada nunca é coisa boa, mas condição inevitável para superar gargalos econômicos, sociais e/ou ambientais. Portanto: quanto menos, melhor.

b) Identidade. Mesmo sendo inevitável e justo por isso, o desenho da estrada deve guardar perfeita sintonia com os seus objetivo e ambiente de instalação.

c) Ambientalismo moderno. Uma boa medida para reduzir impacto ambiental é aquela que, paradoxalmente, se traduz em ganhos econômicos futuros.

As estradas parque são exemplos de vias cuja vocação ambiental evoca o planejamento, projeto, construção, operação e manutenção. Mas no Brasil, o conceito de estrada parque do ponto de vista da mobilidade do tráfego é ainda incipiente. Elas também carecem de melhor embasamento quanto a infraestrutura de transportes rodoviários. Em DNIT (1997) e DNIT (2006), por exemplo, encontram-se 101 definições para diferentes tipos de estradas. Nenhuma delas é de estrada parque.

O conceito corrente atual sobre estrada parque está associado à sua função eminentemente turística e recreativa, e distante dos interesses vinculados ao tráfego de veículos, de cargas e pessoas. A Fundação SOS Mata Atlântica (2004), por exemplo, define estrada parque como um museu permanente de percurso que atravessa Unidades de Conservação ou áreas de relevante interesse ambiental e paisagístico, com o objetivo de aliar a preservação ambiental ao desenvolvimento sustentável da região. Para o Ministério do Turismo (2012), estrada parque tem por objetivo manejar e manter a estrada ou rodovia (ou parte dela) e sua paisagem em estado natural ou seminatural, proporcionando usos recreativo e educativo. Soriano (2006) define estrada parque como uma unidade de conservação de grande beleza cênica, cujo formato e dimensões são definidos pela percepção das paisagens naturais e 
a) Classificação administrativa $\rightarrow$ federais; estaduais; municipais; e particulares, de acordo com o órgão gestor.

b) Quanto à funcionalidade $\rightarrow$ arteriais; coletoras; ou locais, de acordo com a mobilidade, volume de tráfego e velocidades operacionais.

c) Características físicas $\rightarrow$ não pavimentadas; pavimentadas, com pistas simples ou duplas.

d) Padrão técnico $\rightarrow$ com base na sua relevância econômica, descrita em função do tráfego (volume diário médio), e na capacidade de serviço (velocidade média operacional), discriminados no Quadro 1.

Quadro 1. Critérios de classificação de rodovias.

\begin{tabular}{|c|c|c|c|c|c|c|}
\hline \multirow{2}{*}{\multicolumn{2}{|c|}{$\begin{array}{l}\text { CLASSE DE } \\
\text { PROJETO } \\
\text { (1) }\end{array}$}} & \multirow{2}{*}{ CARACTERISTICAS } & \multirow{2}{*}{$\begin{array}{l}\text { CRITÉRIO DE } \\
\text { CLASSIFICAÇÃO } \\
\text { TÉCNICA }\end{array}$} & \multicolumn{3}{|c|}{$\begin{array}{l}\text { VELOCIDADE DE PROJETO POR } \\
\text { REGLÃO }(\mathrm{km} / \mathrm{h})\end{array}$} \\
\hline & & & & Plana & Ondulada & Montanhosa \\
\hline & 0 & $\begin{array}{l}\text { Via Expressa - controle } \\
\text { total de acesso }\end{array}$ & Decisão administrativa & 120 & 100 & 80 \\
\hline \multirow[t]{2}{*}{ I } & $A$ & $\begin{array}{l}\text { Pista dupla - Controle } \\
\text { parcial de acesso }\end{array}$ & $\begin{array}{l}\text { O volume de tráfego previsto } \\
\text { reduzirá o nivel de serviço em } \\
\text { uma rodovia de pista simples } \\
\text { abaixo do nivel "C" } \\
\text { (4) }\end{array}$ & \multirow{2}{*}{100} & \multirow[t]{2}{*}{80} & \multirow{2}{*}{60} \\
\hline & B & Pista simples & $\begin{array}{l}\text { Volume horário de projeto } \\
\text { VHP }>200 \\
\text { Volume médio diário } \mathrm{VMD}> \\
1400\end{array}$ & & & \\
\hline \multicolumn{2}{|c|}{ II } & Pista simples & $\begin{array}{l}\text { Volume médio diário VMD } \\
700-1400\end{array}$ & 100 & 70 & 50 \\
\hline \multicolumn{2}{|c|}{ III } & Pista simples & $\begin{array}{l}\text { Volume médio diário } \mathrm{VMD} \\
300-700\end{array}$ & 80 & 60 & 40 \\
\hline \multicolumn{2}{|c|}{ IV } & Pista simples & $\begin{array}{l}\text { Volume médio diário } \mathrm{VMD}< \\
300\end{array}$ & $\begin{array}{l}80-60 \\
\text { (3) }\end{array}$ & (3) $60-40$ & $40-30$ \\
\hline
\end{tabular}

Fonte: Manual de Implantação Básica de Rodovia (DNIT, 2010).

\section{b) Classificação de acordo com o DER}

O Departamento de Estradas de Rodagem do Estado de São Paulo (DER, 2012) classifica as estradas em vias urbanas e rurais, de acordo com o número de pistas, de faixas, e velocidade de operação. As vias rurais dividem-se em rodovias e estradas, com ênfase à qualidade do tráfego: número de pistas, de faixas, e velocidade operacional. Nas estradas, tais variáveis são mais restritivas.

Para o DER do Paraná (2000), "é importante ter mente que um grande número de alternativas pode ser gerado, envolvendo modos de transporte, capacidade ofertada, níveis de serviço oferecidos e características geométricas e físicas da infraestrutura". Por outro lado, a mesma entidade sugere que os impactos ambientais possam constituir variável básica da seleção, gerando alternativas fora do escopo tradicional e escolhas inviáveis, sem a inclusão da variável ambiental. O mesmo estudo (DER, 2000) propõe ainda um conjunto de medidas e ações relacionado ao projeto geométrico e ao traçado da via, à construção e à operação, com o objetivo de valorizar as questões ambientais. 


\section{c) Classificação de acordo com a AASHTO}

A classificação adotada pela American Association of State Highway and Transportation Officials (AASHTO, 2011) admite a utilização da rodovia como referência para determinar a sua hierarquia na malha viária. Para a AASHTO (2012) as vias estão divididas em três categorias de acordo com a sua utilização, em: arteriais, coletoras e locais.

\section{O CONCEITO DE ESTRADAS PARQUE}

A definição e o conceito correntemente aceitos de estradas parque estão relacionados fortemente à sua função turística (recreação, lazer, cênica e paisagística). Mas as suas características técnicas de engenharia não estão incluídas nos manuais de procedimentos, instruções e métodos executivos dos órgãos brasileiros responsáveis pela infraestrutra viária. Ações de controle e interação ambientais aparecem de maneira difusa na gestão, sobretudo para o licenciamento ambiental da obra. Como resultado, há dispersão na formatação de procedimentos (planejamento, projeto, construção, operação, controle e manutenção), permitindo incluir grande diversidade de vias no escopo das estradas parque.

Em Mato Grosso, a Lei $n^{0} 6.142$ de 17 de dezembro de 1992, dispõe sobre a criação de estradas parque. Destaca-se, contudo, o seu caráter eminentemente recreativo. "Entende-se por estrada parque um parque linear que compreende a totalidade ou parte de rodovias de alto valor panorâmico, cultural ou recreativo". Esta Lei (Artigo 3ำ parágrafo 2ㅇ) ainda subordina a administração destas vias ao órgão ambiental do Estado.

A Funtac (1999) define estrada parque como uma rodovia com sistema de circulação integrado ao meio ambiente e características específicas quanto ao projeto de engenharia.

O manual da AASHTO (2011) sugere que as estradas parque (parkways) são diferentes das estradas comuns. O seu desenho é distinto porque as velocidades operacionais são, geralmente, inferiores, os movimentos de conversão são mais suaves e grandes caminhões são proibidos de trafegar.

Tricárico et al (2012) identificam várias estradas parque, intervenções no seu entorno, equipamentos, instalações e assessórios respectivos. Os autores admitem as estradas parque como "corredores verdes e ecológicos para a migração de organismos vivos, concomitantes com usos antrópicos essencialmente turísticos", e também como oportunidade ao ócio, ao lazer e ao turismo.

Soriano (2006) considera que a indefinição sobre estradas parque "coloca em risco não somente a conservação da biodiversidade como possibilita a manipulação das políticas ambientais pelos mais diferentes grupos de interesse, por justificar a construção irresponsável de estradas em áreas que dificilmente, devido a questão ambiental, seriam autorizadas". Soriano admite estradas parque como unidades de conservação.

Em Funtac (2000) há informações sobre projetos especiais para três segmentos da Rodovia Federal BR 364 no Estado do Acre. Estes trechos, localizados em terras indígenas, estão identificados como: Ecovia Katukinas; Caminho Shanenawa; e Ramal Huni Kui. A relação de 
ações e intervenções inclui: planejamento, projeto, construção, instalações, serviços, operação, e instrução e comunicação aos trabalhadores, comunidade indígena e demais usuários da via. O mesmo documento sugere ainda um programa de acompanhamento da eficácia das medidas propostas. Muitas medidas não foram cumpridas nem integralizadas nas fases posteriores de construção e operação.

Dalponte (2016) descreve algumas dificuldades recorrentes das estradas parque. $\mathrm{O}$ autor propôs instalações e equipamentos para uma estrada parque como condicionante ao licenciamento ambiental. Mas as suas propostas foram solenemente ignoradas pelas autoridades. Mesmo assim a via foi construída e "passados dois anos, nenhuma das ações de mitigação propostas pelo estudo foi executada".

\section{ESTRADAS PARQUE: DISCUSSÃO, RESULTADOS E PROPOSTAS}

\subsection{Discussão Sobre o Conceito de Estrada Parque}

A literatura brasileira sobre estradas e rodovias é abundante e consistente. Além das técnicas e métodos construtivos, vários autores e organismos de gestão da infraestrutura de transportes descrevem sobre a gestão dos recursos ambientais em obras rodoviárias. Mas no caso das estradas parque o registro acerca das características geométricas (base para os projetos de drenagem, terraplenagem, pavimentação), das técnicas construtivas e de controle operacional é ainda pouco e disperso.

O Glossário de Termos Técnicos Rodoviários (DNIT, 1997), por exemplo, registra 45 definições para diferentes tipos de estradas. O Glossário de Termos Técnicos Ambientais Rodoviários (DNIT, 2006) identifica outros 63 tipos de estradas e rodovias. Nenhuma delas, porém, é de estrada parque.

Pedro e Lima (2014) comentam sobre a necessidade de alterar paradigmas do projeto geométrico de estradas. Para estes autores, incluir os "pontos obrigatórios de não passagem" vinculados aos cenários de instalação das estradas poderá resultar em significativa colaboração à melhor interface entre estradas e ambientes.

Embora as instruções sobre estradas parque sejam ainda carentes na literatura, há registros de estradas parque em diversas unidades da federação. Muitas destas vias, no entanto, adotam apenas o nome (estrada parque) como "batismo" e estratégia de marketing. Encontram-se informações sobre estradas parque em São Paulo, Minas Gerais, Bahia, Paraná, Goiás, Mato Grosso do Sul, Roraima, Rio de Janeiro, Espírito Santo e Acre. No Distrito Federal há indicação de 25 segmentos de estradas parque.

Há vias identificadas como estradas parque não subordinadas aos órgãos públicos de gestão da malha viária. Em muitos casos, elas são administradas pelas Secretarias de Turismo ou de Gestão Ambiental. Esta difusão de responsabilidades dificulta o registro histórico e a análise dos sucessos e fracassos, capazes de fomentar e consolidar estradas parque como alternativas de tráfego. Inviabiliza também padronizar e uniformizar o acervo de procedimentos e a evolução das técnicas construtivas, equipamentos e assessórios, e de 
controle das operações. Restringe ainda as suas identificação e localização na malha rodoviária e a aplicação de sistemas de gerência e manutenção da própria via.

\subsection{Estradas Parque e a Infraestrutura de Transportes}

De maneira geral, os conceitos de estradas parque não vinculam os serviços ambientais aos critérios técnicos adotados em vias tradicionais de tráfego. Mas as variáveis para qualificar estradas parque excedem as condicionantes formais implícitas na literatura clássica e nos manuais de estradas e rodovias. Por outro lado, não parece oportuno definir estradas parque como "estradas ecológicas", "parques lineares"; "estradas verdes", ou mesmo "unidades de conservação", visto que as estradas (qualquer estrada) são agentes intrínsecos de fortes e continuadas alterações ambientes. Ademais, as estradas parque não estão (nem devem estar) circunscritas apenas aos limites das unidades de conservação. Pelo contrário, a sua relevância espacial precisa expandir e alcançar extensões e cenários diversos além das áreas protegidas, inclusive urbanos e periurbanos.

Estradas parque são vias especiais cujos parâmetros de projeto, construção e operação são diferentes daqueles tradicionalmente aceitos e aplicados no âmbito da infraestrutura de transportes. Elas adotam critérios ambientais como referência e um conjunto de equipamentos, assessórios e serviços estranhos àquelas (zoopassagens, telas de proteção, pátios para contemplação, portais). Mas além dos equipamentos e serviços especiais, as estradas parque requerem um conjunto de atributos que lhes permitam oferecer tráfego seguro e confortável (mobilidade) aos usuários. Assim, a geometria e o traçado da via com os seus raios de curvatura, inclinações e concordâncias, distâncias de visibilidade, devem preservar consonância com o ambiente vizinho. Da mesma forma, as dimensões da plataforma: faixas de domínio, faixas de tráfego e acostamentos requerem padronização de acordo com a fragilidade ambiental da região.

\subsection{Algumas Propostas para as Estradas Parque}

Dado que o volume de tráfego e a velocidade operacional nas estradas parque são menores, os veículos mais leves, e mais simples "acomodação" à topografia do terreno, é válido supor que elas ocupem menor superfície que as vias tradicionais. Tal condição implica em redução das resultantes da fragmentação e ressecamento de borda, das alterações no balanço hídrico, e ainda facilita a perambulação de animais silvestres.

É comum sobrepor o traçado das estradas parque ao leito de vias preexistentes. Este procedimento reduz a demanda por supressão extra de vegetação e de movimentos de terra (cortes e aterros). Desta forma, a patrulha de máquinas, equipamentos, a equipe de trabalhadores, e os próprios serviços podem ser reduzidos. Dentre as consequências diretas advindas daí destacam-se: menores volumes de ruídos; de vibração; de emissão de gases e 


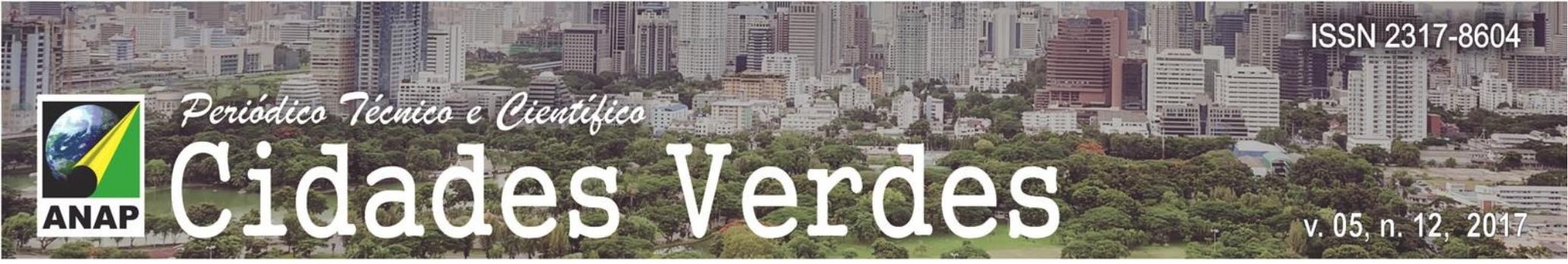

particulados; de produção de lixo e rejeitos. A definição do traçado da via deve ainda considerar os custos operacionais e as emissões (gases) futuros - na fase de operação.

A aproximação e o cruzamento com mananciais e corpos d'água devem ser objeto de detida análise durante o planejamento e definição da geratriz da estrada. A vulnerabilidade destes ambientes recomenda identificar as regiões mais apropriadas, de modo a reduzir os impactos e os conflitos potenciais entre os meios terrestre e fluvial.

Aos procedimentos tradicionalmente adotados para minimizar os impactos durante a fase de construção podem-se somar, no caso das estradas parques: restringir a localização e a exploração de jazidas, empréstimos e bota-fora; limitar os horários de trabalho; instruir a equipe de colaboradores e a comunidade local sobre as particularidades de obra.

Os materiais empregados na construção da via devem ter reduzido potencial contaminante. Prevenir vazamentos e contaminação do solo, do ar, de corpos d'água e de outros materiais durante o manejo e a estocagem desses produtos. Deve-se ainda restringir o uso de materiais que possam alterar as suas propriedades químicas / mineralógicas com o tempo ou em contato com outros materiais e produtos.

Os equipamentos de drenagem devem prevenir a erosão e o assoreamento na faixa de rolamento e nas bordas da pista e permitir o escoamento superficial das águas. Observando o ambiente da obra, podem-se adotar métodos compensatórios (compensar os efeitos da impermeabilização de superfície) para os dispositivos de drenagem, com uso intenso de materiais permeáveis, inclusive no revestimento do pavimento rodoviário.

A Figura 1 mostra um pavimento cujo revestimento (permeável) é construído com blocos vazados de concreto pré-moldado. Neste caso, o conforto e a beleza cênicos ampliam a percepção de integração da obra ao ambiente. Na Figura 2 destaca-se um trecho da SP 319 (Estrada Parque Nequinho Fogaça), em que via é desprovida de acostamento e faixa de domínio é preservada com vegetação. A Figura 3 é um trecho da Ecovia Katukina (BR 364) no Estado do Acre, desprovido das medidas mitigadoras propostas no planejamento original. Este segmento da rodovia, localizado em terra indígena, é semelhante àqueles localizados fora da área protegida. 


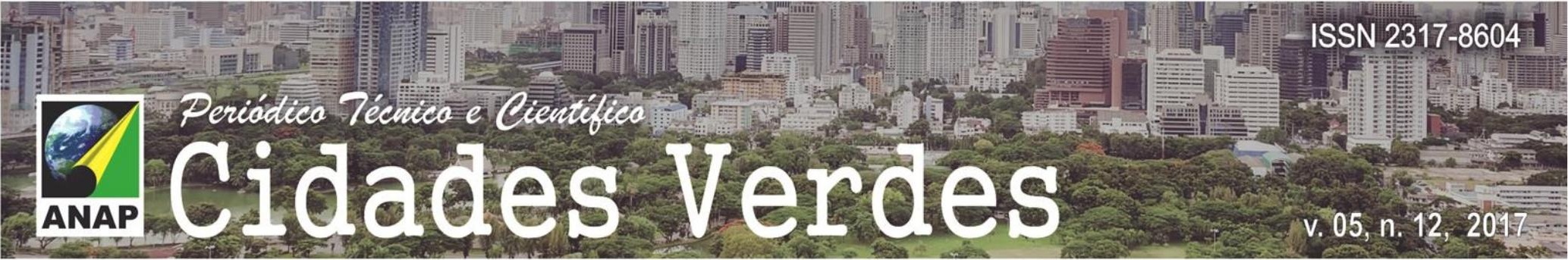

Figura 1. Vias com revestimentos permeáveis de blocos vazados de concreto pré-moldado.

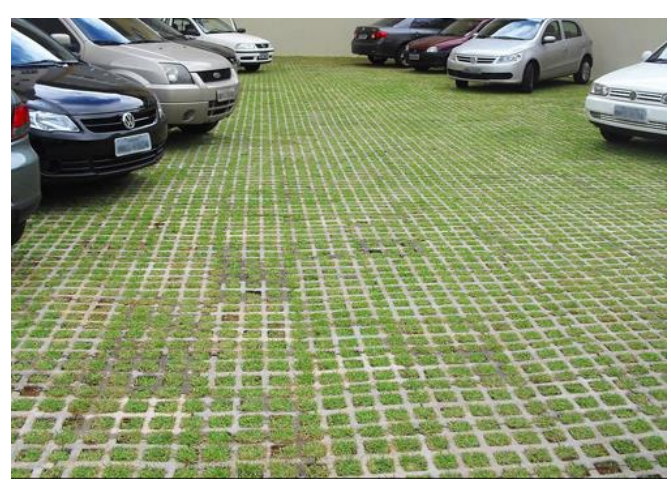

Fonte:

https://tecparpavimentos.files.wordpress.com/2012/05/p avimentac3a7c3a3o-ecolc3b3gica.jpg . Acesso 23/05/2017

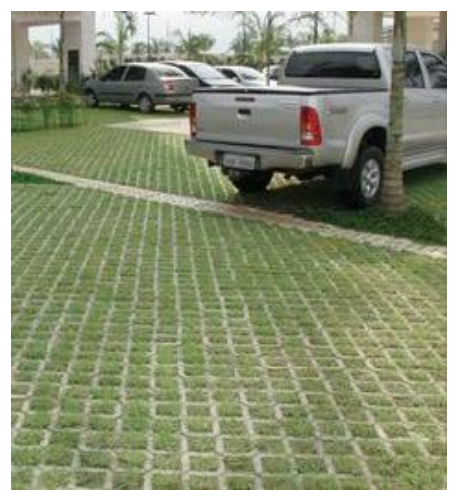

Fonte: https://s-media-cacheak0.pinimg.com/236x/4c/57/0e/4c570e9f86a9176e544 b12997629f01d.jpg

A possibilidade de drenar as águas pluviais no próprio local reduz a vazão final, a velocidade do escoamento e, por analogia, a sua capacidade erosiva. Além disso, inibe a necessidade de grandes sarjetas e obras de contenção, de dispositivos de redução de velocidade das águas e de bacias de dissipação.

Figura 2. Revestimento articulado com blocos concreto pré-moldado na Estrada Parque Nequinho Fogaça.

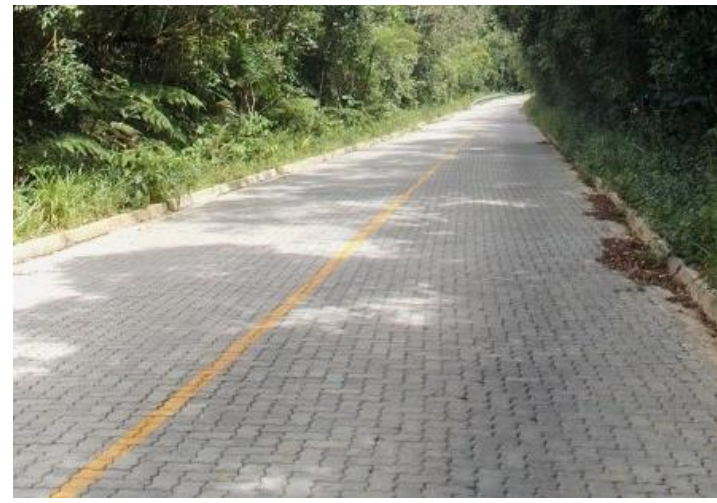

Fonte: http://www.ambiente.sp.gov.br/parque-carlos-botelho/2012/05/16/estrada-parque-da-sede-aonucleo-sete-barras/. Acesso 01/12/2016. 


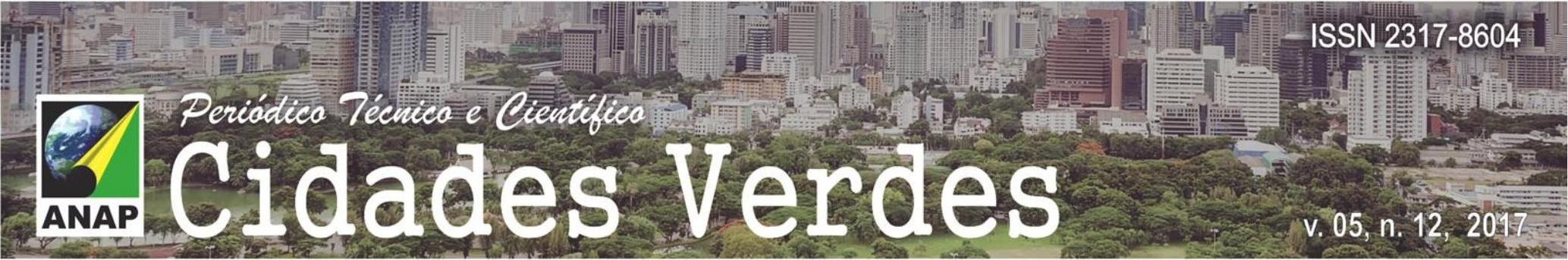

Figura 3. Barreiras anti-ruídos.

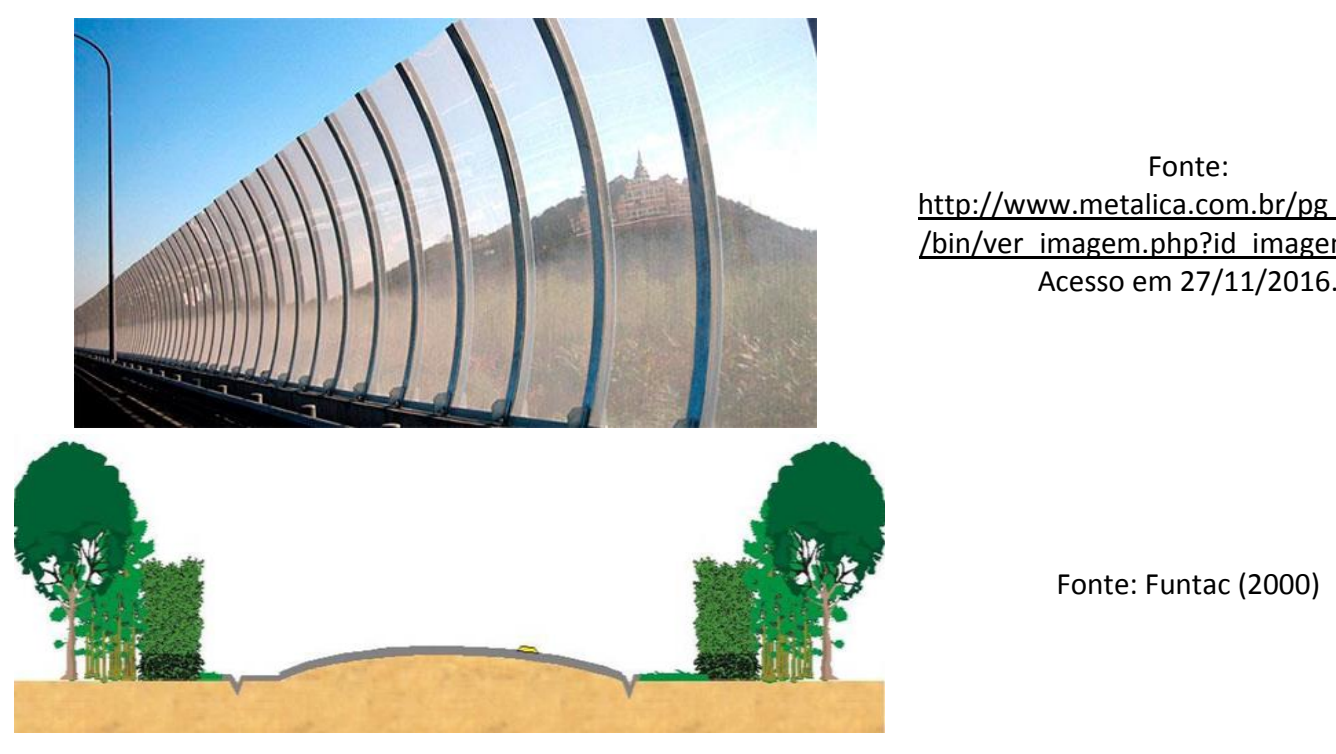

b) Fase de operação

Adotar programas continuados de educação no trânsito, de prevenção de acidentes e de respeito ao ambiente, sobretudo nos trecho em que a estrada atravessa unidades de conservação ou em cenários com riscos e sensíveis ambientalmente. No caso das estradas parque em unidades de conservação restringir ainda, e se possível, o tráfego de veículos pesados e operações em período noturno.

Sinalização especial para alertar os usuários sobre as restrições operacionais da via, e fiscalização das operações.

Manter um programa contínuo com registros atualizados sobre todas as ocorrências no curso da estrada, a sua localização, horário, e demais informes capazes de gerar diagnósticos consistentes e precisos. Este estoque de informações e dados poderá subsidiar planos de ordenamento territorial (na estrada e na sua área de influência), de avaliação dos equipamentos, instalações e serviços, das intervenções e suas eficácias respectivas.

\section{CONCLUSÕES}

Estradas parque não são simples estradas por onde circulam veículos com suas cargas e passageiros, como sugerem os critérios tradicionais de classificação. Tampouco são apenas parques destinados aos turistas em suas viagens de recreação e lazer, ou de proteção de ecossistemas próximos às instalações da via.

A definição de estradas parque pode estar menos associada aos serviços turísticos prestados pela via acabada, e mais às qualidades simultâneas de integração ambiental e manutenção das condições de tráfego. E esta concordância deve prevalecer nos seus planejamento, projeto, definição e escolha do traçado, dos materiais e equipamentos construtivos, operações e controle do tráfego, e manutenção. 


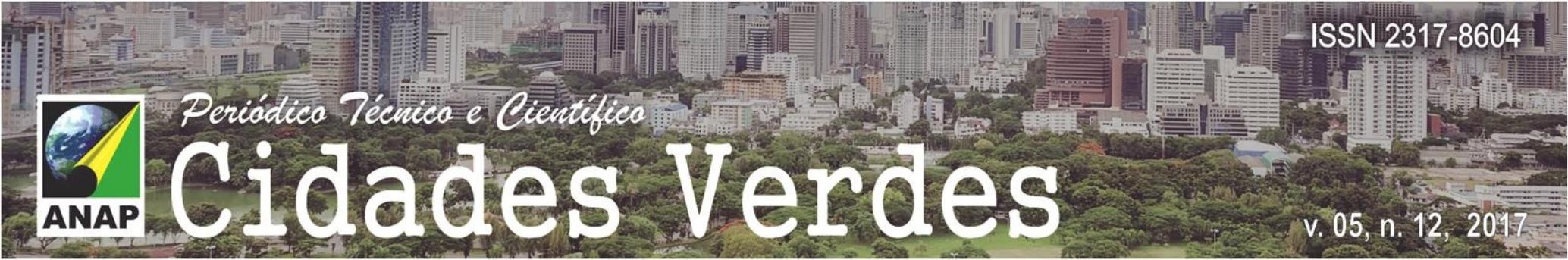

PEDRO, B. G.; Lima, J. S. P. L. Projeto geométrico de rodovias: avaliação sobre os pontos obrigatórios de (não) passagem com relevância ambiental. In: XXVI CONGRESSO DE INICIAÇÃO CIENTÍFICA DA UNESP, 2014. Anais... Ilha Solteira. 2014. Disponivel em: http://prope.unesp.br/cic_isbn/fase_1.php?mn=3

SORIANO, Afrânio José Soares. Estrada-parque: proposta para uma definição. Tese de Doutorado. Universidade Estadual Paulista, Instituto de Geociências e Ciências Exatas, Rio Claro, 2006. 181p.

TRICÁRICO, Luciano Torres; Oliveira, Josildete Pereira de; Rossini, Diva de Mello; Carvalho, Débora Ioná. Estradas-parque: um estudo comparativo no intuito de definições para a experiência turística brasileira. Revista Brasileira de Pesquisa em Turismo. São Paulo, 6(1), pp. 79-94. Abril de 2012. 